\title{
Synthesis of new pyrrolidine-based organocatalysts and study of their use in the asymmetric Michael addition of aldehydes to nitroolefins
}

\author{
Alejandro Castán, Ramón Badorrey*, José A. Gálvez and María D. Díaz-de-Villegas*
}

\author{
Full Research Paper \\ Address: \\ Instituto de Síntesis Química y Catálisis Homogénea (ISQCH), CSIC - \\ Universidad de Zaragoza, Departamento de Química Orgánica, Pedro \\ Cerbuna 12, E-50009 Zaragoza, Spain \\ Email: \\ Ramón Badorrey ${ }^{*}$ - badorrey@unizar.es; \\ María D. Díaz-de-Villegas* - loladiaz@unizar.es \\ * Corresponding author \\ Keywords: \\ enantioselective synthesis; Michael addition; organocatalysis; \\ pyrrolidines; synthetic methods
}

Open Access

\author{
Beilstein J. Org. Chem. 2017, 13, 612-619.
}

doi:10.3762/bjoc.13.59

Received: 26 October 2016

Accepted: 09 March 2017

Published: 27 March 2017

This article is part of the Thematic Series "Strategies in asymmetric catalysis".

Guest Editor: T. P. Yoon

(C) 2017 Castán et al.; licensee Beilstein-Institut.

License and terms: see end of document.

\begin{abstract}
New pyrrolidine-based organocatalysts with a bulky substituent at $\mathrm{C} 2$ were synthesized from chiral imines derived from $(R)$-glyceraldehyde acetonide by diastereoselective allylation followed by a sequential hydrozirconation/iodination reaction. The new compounds were found to be effective organocatalysts for the Michael addition of aldehydes to nitroolefins and enantioselectivities up to $85 \%$ ee were achieved.
\end{abstract}

\section{Introduction}

In the first decades of the 21 st century, the enantioselective organocatalysis has witnessed a tremendous development [1-4] and it is now considered to be the third pillar of enantioselective catalyses together with metal complex-mediated catalysis and biocatalysis. Among the different structures usually found in organocatalysis, the five-membered secondary amine structure of pyrrolidine has proven to be a privileged motif [5] with a powerful capacity in aminocatalysis [6-10]. In this context diarylprolinol silyl ethers have proven to be extremely efficient organocatalysts for a wide variety of chemical transformations [11].

In the course of our research we have been involved in the synthesis of new tuneable catalytic motifs to be used in organocatalysis starting from the chiral pool. Highly modular chiral aminodiol derivatives were obtained by the addition of organometallic reagents to chiral imines derived from $(R)$-glyceraldehyde - which is easily accessible from D-mannitol - and 
these were evaluated as chiral organocatalysts in the enantioselective $\alpha$-chlorination of $\beta$-ketoesters, with excellent results obtained after optimisation of the organocatalyst structure [12].

In an effort to identify new, easily accessible and tuneable organocatalysts with the privileged pyrrolidine motif from the chiral pool, we have now focused on the synthesis of new chiral pyrrolidines capable of creating a sterically demanding environment due to the presence of a bulky 2,2-disubstituted-1,3-dioxolan-4-yl moiety at $\mathrm{C} 2$ from chiral imines derived from $(R)$-glyceraldehyde. The Michael addition of aldehydes to nitroolefins was selected as a model reaction to evaluate the effectiveness of the new pyrrolidine-based organocatalysts in aminocatalysis.

\section{Results and Discussion}

We reasoned that pyrrolidines of type $\mathbf{C}$ with a bulky 2,2-disubstituted-1,3-dioxolan-4-yl moiety at $\mathrm{C} 2$ could provide the appropriate environment to lead to high levels of enantioselectivity in asymmetric transformations in which enamine intermediates are formed. The substituent $\mathrm{R}^{1}$ in the 1,3-dioxolane moiety in pyrrolidines $\mathbf{C}$ could be varied to modulate the reactivity and selectivity of the new organocatalysts.

The sequential hydrozirconation/iodination of chiral homoallylic amines has been described as a straightforward approach to enantiomerically pure 2-substituted pyrrolidines $[13,14]$. Therefore we decided to test this methodology to gain access to the pyrrolidine ring in compound $\mathbf{C}$. The required chiral homoallylic amines $\mathbf{B}$ can be easily obtained by the addition of allylmagnesium bromide to imines derived from $(R)$-glyceraldehyde acetonides A (Figure 1) according to our previously de- scribed methodology [15]. The configuration at C2 of the pyrrolidine ring would be determined in the diastereoselective allylation of the starting chiral imines.

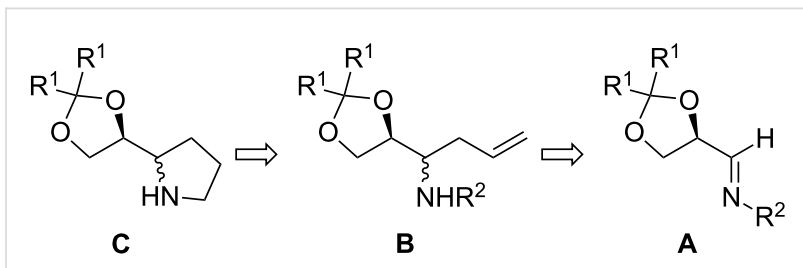

Figure 1: Strategy for the preparation of 2-substituted pyrrolidines C

The homoallylic amine $\mathbf{1}$ with syn-configuration was obtained by the reaction of the corresponding imine with allylmagnesium bromide as previously described [15]. The amine $\mathbf{1}$ was reacted with the Schwartz reagent in $\mathrm{CH}_{2} \mathrm{Cl}_{2}$ at room temperature to afford the hydrozirconated intermediate, which was immediately treated with iodine to yield $N$-benzylpyrrolidine 2 in $69 \%$ isolated yield. The subsequent exposure of compound 2 to molecular hydrogen in the presence of $\mathrm{Pd}(\mathrm{OH})_{2} / \mathrm{C}$ as a catalyst afforded the desired organocatalyst OC1 in 73\% yield (Scheme 1).

The same reaction sequence led to organocatalyst OC2 in 52\% overall yield starting from homoallylic amine $\mathbf{3}$ having anticonfiguration, which was obtained by reaction of the corresponding $\mathrm{BF}_{3} \cdot \mathrm{OEt}_{2}$ pre-complexed imine with allylmagnesium bromide as previously described [15] (Scheme 2). It is worth mentioning that the starting homoallylic amines $\mathbf{1}$ and $\mathbf{3}$ can be obtained on a multigram scale from the chiral pool.

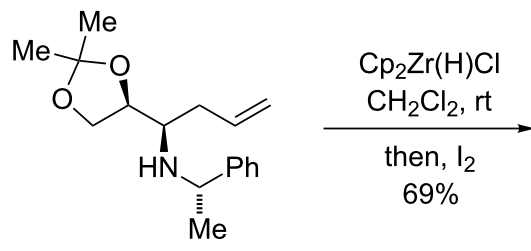

1

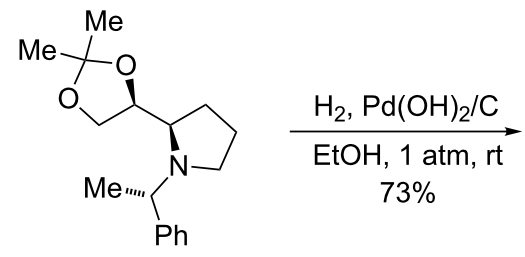

2

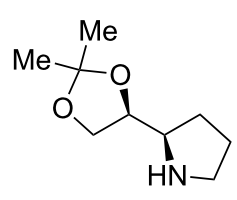

oc1

Scheme 1: Synthesis of the new organocatalyst OC1.

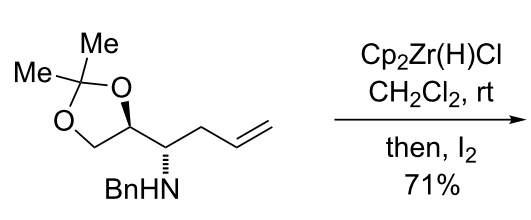

3

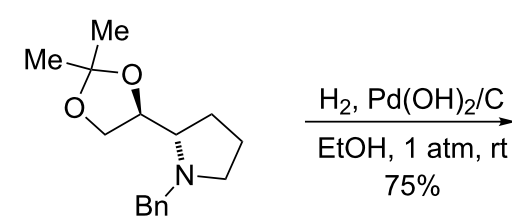

4

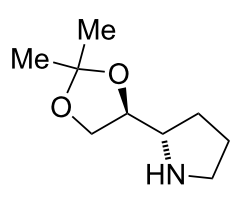

OC2 
In order to obtain a series of new organocatalysts with substituents of different sizes and stereoelectronic properties in the dioxolane moiety, the following reaction sequence was applied to compounds 2 and 4: a) N-deprotection by hydrogenolysis of the benzylic group with molecular hydrogen using $\mathrm{Pd}(\mathrm{OH})_{2} / \mathrm{C}$ as a catalyst in the presence of trifluoroacetic acid, b) reprotection of the amino group as benzylcarbamate by treatment of the crude reaction mixture with benzyl chloroformate in the presence of diisopropylethylamine, c) hydrolysis of the dioxolane moiety with trifluoroacetic acid, d) reconstruction of the dioxolane moiety by reaction of the diol with the corresponding dimethoxyacetal in the presence of $\mathrm{SnCl}_{2}$ and e) N-deprotection of the pyrrolidine by exposure of the benzylcarbamate to molecular hydrogen in the presence of catalytic $\mathrm{Pd} / \mathrm{C}$. In this way organocatalysts OC3-OC10 were obtained (Scheme 3 and Scheme 4).
In addition another new organocatalyst, OC11, with a different bulky substituent at $\mathrm{C} 2$ in the pyrrolidine moiety was prepared. Reacting diol 7 with 1,3-dichlorotetraisopropyldisiloxane in the presence of imidazole and subsequent hydrogenolysis of the benzylcarbamate with molecular hydrogen in the presence of catalytic $\mathrm{Pd} / \mathrm{C}$ (Scheme 5) afforded OC11 in 43\% overall yield for the two steps.

With this series of pyrrolidines at hand, the well-established Michael addition of aldehydes to nitroolefins [16-18] was selected as a benchmark reaction to study their behaviour as organocatalysts. Compounds with a related structure prepared from proline by Diez et al. have proven to work well as organocatalysts in the Michael addition of cyclohexanones to nitrostyrenes $[19,20]$.
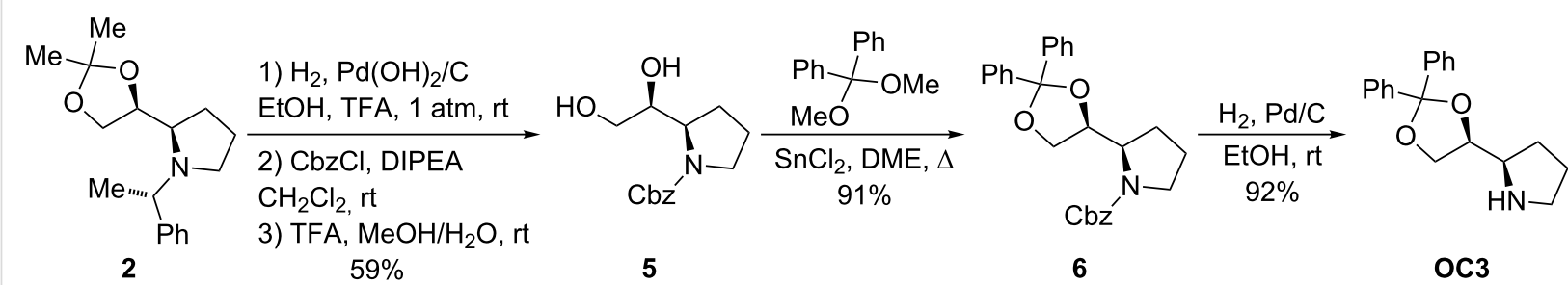

Scheme 3: Synthesis of new organocatalyst OC3.

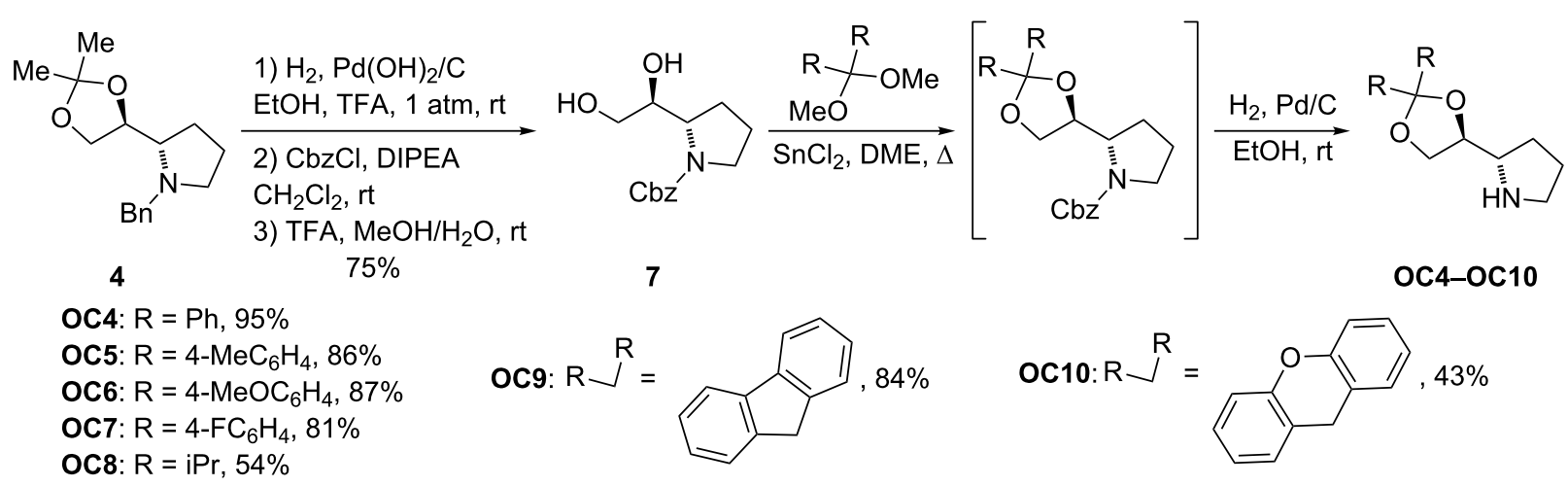

Scheme 4: Synthesis of new organocatalysts OC4-OC10.<smiles>O=C(c1ccccc1)N1CCCC1C(O)CO</smiles>

7

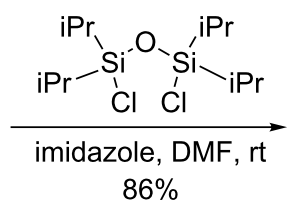
$86 \%$<smiles>CC(C)C1(C(C)C)OCC(C2CCCN2C(=O)O)O[Si](C(C)C)(C(C)C)O1</smiles>

8<smiles>CC(C)[Si]1(C(C)C)OCC(C2CCCN2)O[Si](C(C)C)(C(C)C)O1</smiles>

oc11 
We first tested organocatalysts OC1-OC4 in the reaction of trans- $\beta$-nitrostyrene with 3-phenylpropionaldehyde in order to determine the influence that the relative configuration of the pyrrolidine had on the results (Table 1). The reaction was initially carried out at room temperature in the presence of $10 \mathrm{~mol} \%$ of the catalyst and using $\mathrm{CH}_{2} \mathrm{Cl}_{2}$ as solvent. Under these conditions the yield of the Michael adducts was 95-99\% within 7 hours. The diastereoselectivity was moderate $(\mathrm{dr}=$ 70:30-78:22) in favour of the syn-diastereoisomer and enantio- selectivites were ee $\approx 68 \%$ for the $s y n$-adducts and ee $=44-63 \%$ for the anti-adducts. The stereochemistry of the major compound depended on the stereochemistry of the organocatalyst and Michael adducts of opposite configuration were obtained on using syn or anti-pyrrolidines with similar levels of enantioselectivity for the major syn-diastereoisomer.

Next, the effect of the solvent and temperature was studied using OC4 as the organocatalyst (Table 2). The best results

Table 1: Initial screening of catalysts for the Michael addition of 3-phenylpropionaldehyde to trans- $\beta$-nitrostyrene. ${ }^{a}$

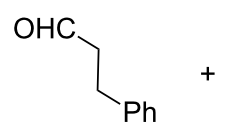<smiles>O=[N+]([O-])C=Cc1ccccc1</smiles>

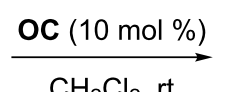<smiles>O=C[CH]c1cccc(C(C[N+](=O)[O-])C(C=O)Cc2ccccc2)c1</smiles>

9 a

\begin{tabular}{cccccc}
\hline Catalyst & $t(\mathrm{~h})$ & Yield $^{\mathrm{b}}(\%)$ & syn:anti & ee syn $(\%)$ & -68 \\
OC1 & 7 & 95 & $70: 30$ & 68 & -63 \\
OC2 & 7 & 97 & $78: 22$ & 76 & -68 \\
OC3 & 7 & 99 & $74: 26$ & -44 \\
OC4 & 7 & 96 & $77: 23$ & 66 & 44 \\
\hline
\end{tabular}

aReaction performed in $\mathrm{CH}_{2} \mathrm{Cl}_{2}(2 \mathrm{~mL})$ at room temperature using $0.2 \mathrm{mmol}$ of $\beta$-nitrostyrene, $0.4 \mathrm{mmol}$ of 3 -phenylpropionaldehyde and 10 mol \% of catalyst. ${ }^{b}$ Determined from the crude reaction mixture by ${ }^{1} \mathrm{H}$ NMR spectroscopy using $1,3,5$-trimethoxybenzene as internal standard. ${ }^{\mathrm{C}}$ Determined by chiral HPLC.

Table 2: Optimization of the reaction conditions for the Michael addition of 3-phenylpropionaldehyde to trans- $\beta$-nitrostyrene using catalyst OC4. ${ }^{\text {a }}$

\begin{tabular}{|c|c|c|c|c|c|c|}
\hline \multirow[b]{2}{*}{ Solvent } & \multicolumn{2}{|l|}{+} & $\frac{\mathrm{C} 4(10 \mathrm{~mol} \%)}{\text { solvent, } T}$ & \multicolumn{2}{|c|}{$9 a$} & \multirow[b]{2}{*}{ ee $a n t i c(\%)$} \\
\hline & $T\left({ }^{\circ} \mathrm{C}\right)$ & $t(\mathrm{~h})$ & Yield $^{\mathrm{b}}(\%)$ & syn:antib & ee $\operatorname{syn}^{c}(\%)$ & \\
\hline $\mathrm{CH}_{2} \mathrm{Cl}_{2}$ & $\mathrm{rt}$ & 7 & 96 & $77: 23$ & 66 & 44 \\
\hline THF & $\mathrm{rt}$ & 7 & 86 & $80: 20$ & 71 & 51 \\
\hline toluene & $\mathrm{rt}$ & 7 & 82 & $84: 16$ & 74 & 44 \\
\hline $\mathrm{CHCl}_{3}$ & $\mathrm{rt}$ & 7 & 89 & $78: 22$ & 57 & 43 \\
\hline $\mathrm{EtOH}$ & $\mathrm{rt}$ & 7 & 85 & $76: 24$ & 62 & 21 \\
\hline cyclohexane & $\mathrm{rt}$ & 7 & 87 & $86: 14$ & 81 & 67 \\
\hline MTBE & $\mathrm{rt}$ & 7 & 96 & $87: 13$ & 63 & 35 \\
\hline $\mathrm{MeCN}$ & $\mathrm{rt}$ & 7 & 87 & $77: 23$ & 57 & 23 \\
\hline $\mathrm{CF}_{3} \mathrm{C}_{6} \mathrm{H}_{4}$ & $\mathrm{rt}$ & 7 & 93 & $89: 11$ & 78 & 75 \\
\hline $\mathrm{C}_{6} \mathrm{~F}_{6}$ & $\mathrm{rt}$ & 7 & 90 & $92: 8$ & 80 & 62 \\
\hline $\mathrm{C}_{6} \mathrm{~F}_{11} \mathrm{CF}_{3}$ & $\mathrm{rt}$ & 7 & 85 & $68: 32$ & 76 & 74 \\
\hline $\mathrm{C}_{10} \mathrm{~F}_{8}$ & $\mathrm{rt}$ & 7 & 82 & $73: 27$ & 76 & 73 \\
\hline methylcyclohexane & 0 & 24 & 87 & $92: 8$ & 85 & 58 \\
\hline toluene & 0 & 24 & 84 & $86: 14$ & 80 & 39 \\
\hline methylcyclohexane & -20 & 24 & 77 & $94: 6$ & 85 & 40 \\
\hline
\end{tabular}

aReaction performed using $0.2 \mathrm{mmol}$ of $\beta$-nitrostyrene, $0.4 \mathrm{mmol}$ of 3-phenylpropionaldehyde and $10 \mathrm{~mol} \%$ of OC4 in the given solvent ( $2 \mathrm{~mL}$ ). ${ }^{b}$ Determined from the crude reaction mixture by ${ }^{1} \mathrm{H}$ NMR spectroscopy using 1,3,5-trimethoxybenzene as internal standard. ${ }^{\mathrm{C}}$ Determined by chiral HPLC. 
were obtained with methylcyclohexane as the solvent at $0{ }^{\circ} \mathrm{C}$ reaction temperature. Under these conditions after $24 \mathrm{~h}$ the reaction yield was high (87\%), the observed diastereoselectivity was 92:8 in favour of the syn-adduct and the enantioselectivity reached $85 \%$ ee for the major syn-adduct. A further decrease in temperature did not improve these results substantially but did diminish the reaction yield (Table 2).

The organocatalysts OC1-OC11 were then screened to reveal the influence of the substituent $\mathrm{R}$ attached to the dioxolane moiety on the reaction outcome and the results are collected in Table 3. However, the variation of this substituent did not result in any significant improvement of the diastereo- or enantioselectivity and based on these results organocatalyst OC4 was found to be the most efficient and stereoselective organocatalyst. It is worth mentioning that on reducing the catalyst loading to $5 \mathrm{~mol} \%$ the reactivity remained good and the diastereoselectivity and enantioselectivity were only slightly affected.

It has been reported that additives present in the reaction medium can lead to improved results without changing other reaction conditions [21]. For example, in secondary aminecatalysed asymmetric reactions a Brønsted acid additive was found to accelerate the formation of the enamine intermediate and thus to improve not only the reactivity but also the diastereoselectivity and enantioselectivity $[22,23]$. On the other hand, the presence of thiourea additives could activate nitroalkenes when used as substrates by double hydrogen bonding, which lead to improved reactivities [24]. Based on these findings, we decided to explore the effect of a Brønsted acid or an achiral thiourea as additive on the reaction between trans- $\beta$ nitrostyrene and 3-phenylpropionaldehyde promoted by OC4 (Table 4). When thioureas were used as additives the reaction was performed in toluene in order to improve the solubility.

The addition of benzoic or acetic acid increased the reactivity and anti-enantioselectivity but it was detrimental for the diastereoselectivity and syn-enantioselectivity. On the other hand, in the presence of trifluoroacetic acid the reaction proceeded slowly and the diastereoselectivity decreased to some extent. The presence of an achiral thiourea did not improve the results.

Finally, we considered the possibility of accelerating the formation of the enamine intermediate and simultaneously activating the nitroalkene by using a combination of organocatalyst $\mathbf{O C 4}$, a Brønsted acid and an achiral thiourea. Thus the reaction was repeated in the presence of a combination of benzoic acid and $N, N$ '-diphenylthiourea (TU1) as additives. The enantioselectivity of both syn and anti-adducts reached quite good values ( $87 \%$ ee and $91 \%$ ee, respectively) but the diastereoselectivity dropped to $67: 33$.

Table 3: Screening of organocatalysts OC1-OC11 for the Michael addition of 3-phenylpropionaldehyde to trans- $\beta$-nitrostyrene. ${ }^{a}$

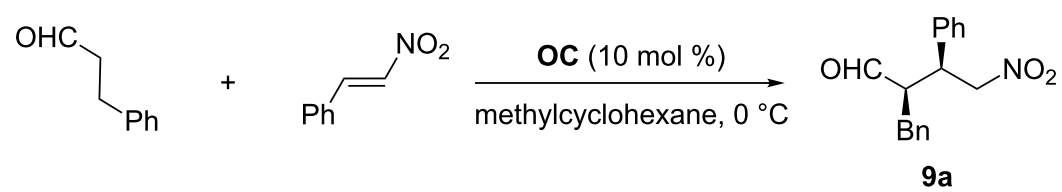

\begin{tabular}{|c|c|c|c|c|}
\hline Catalyst & Yield $^{\mathrm{b}}(\%)$ & syn:antib & ee $\operatorname{syn}^{c}(\%)$ & ee $\operatorname{antic}(\%)$ \\
\hline OC1 & 84 & $84: 18$ & 77 & 72 \\
\hline OC2 & 77 & $94: 6$ & 81 & 50 \\
\hline OC3 & 91 & $78: 22$ & 77 & 65 \\
\hline OC4 & 87 & $93: 7$ & 85 & 58 \\
\hline OC5 & 99 & $92: 8$ & 84 & 63 \\
\hline Oc6 & 86 & $88: 12$ & 80 & 61 \\
\hline OC7 & 90 & $92: 8$ & 83 & 57 \\
\hline OC8 & 91 & $93: 7$ & 73 & 70 \\
\hline OC9 & 93 & $93: 7$ & 76 & n.d. \\
\hline OC10 & 83 & $93: 7$ & 85 & n.d. \\
\hline OC11 & 72 & $87: 13$ & 63 & n.d. \\
\hline$O C 4^{d}$ & 81 & $89: 11$ & 82 & 59 \\
\hline$O C 4^{\mathrm{e}}$ & 23 & $78: 22$ & 82 & 45 \\
\hline
\end{tabular}

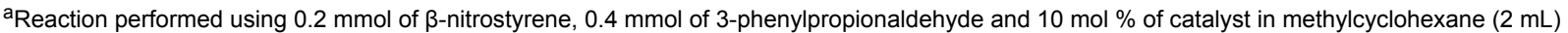
at $0{ }^{\circ} \mathrm{C}$ for $24 \mathrm{~h}$. betermined from the crude reaction mixture by ${ }^{1} \mathrm{H}$ NMR spectroscopy using 1,3,5-trimethoxybenzene as internal standard. ${ }^{\mathrm{c}}$ Determined by chiral HPLC. ${ }^{\mathrm{d} C}$ Catalyst loading $5 \mathrm{~mol} \%$. ${ }^{\mathrm{e} C}$ Catalyst loading $2 \mathrm{~mol} \%$. 
Table 4: Screening of additives for the Michael addition of 3-phenylpropionaldehyde to trans- $\beta$-nitrostyrene using catalysts OC4. $^{\text {a }}$

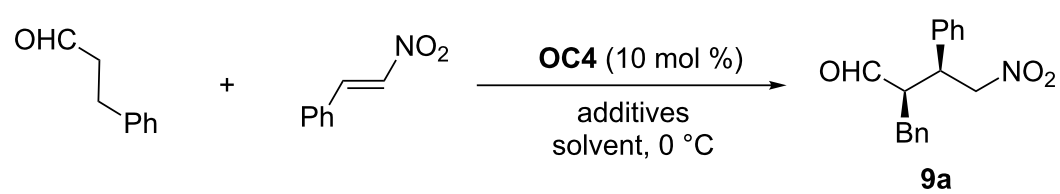

\begin{tabular}{ccccccc}
\hline Acid & TUc & Solvent & Yield $^{\mathrm{d}}(\%)$ & syn:anti $^{\mathrm{d}}$ & ee syn $^{\mathrm{e}}(\%)$ & ee anti $^{\mathrm{e}}(\%)$ \\
\hline none & none & methylcyclohexane & 87 & $93: 7$ & 85 & 58 \\
$\mathrm{PhCO}{ }_{2} \mathrm{H}$ & none & methylcyclohexane & 93 & $75: 25$ & 77 & 83 \\
$\mathrm{AcOH}$ & none & methylcyclohexane & 98 & $60: 40$ & 75 & 83 \\
$\mathrm{TFA}$ & none & methylcyclohexane & 32 & $76: 24$ & 83 & 82 \\
none & none & toluene & 84 & $86: 4$ & 80 & 39 \\
none & TU1 & toluene & 92 & $76: 24$ & 72 & 63 \\
none & TU2 & toluene & 87 & $87: 13$ & 61 & 24 \\
$\mathrm{PhCO}_{2} \mathrm{H}$ & TU1 & toluene & 94 & $67: 33$ & 87 & 91 \\
$\mathrm{AcOH}$ & TU1 & toluene & 90 & $80: 20$ & 80 & 58 \\
$\mathrm{PhCO}_{2} \mathrm{H}$ & TU2 & toluene & 94 & $74: 26$ & 83 & 80 \\
$\mathrm{AcOH}$ & TU2 & toluene & 85 & $90: 10$ & 77 & 36 \\
\hline
\end{tabular}

aReaction performed using $0.2 \mathrm{mmol}$ of $\beta$-nitrostyrene, $0.4 \mathrm{mmol}$ of 3-phenylpropionaldehyde, $10 \mathrm{~mol} \%$ of OC4 and $10 \mathrm{~mol} \%$ of additive in the given solvent $(2 \mathrm{~mL})$ at $0{ }^{\circ} \mathrm{C}$ for $24 \mathrm{~h} .{ }^{\mathrm{b}} \mathrm{AcOH}=$ acetic acid, TFA $=$ trifluoroacetic acid. ${ }^{\circ} \mathrm{TU} 1=N, N$-diphenylthiourea, TU2 $=N, N$-bis[3,5-di(trifluoromethyl)phenyl]thiourea. ${ }^{\mathrm{d}}$ Determined from the crude reaction mixture by ${ }^{1} \mathrm{H}$ NMR spectroscopy using $1,3,5$-trimethoxybenzene as internal standard. e Determined by chiral HPLC.

The aryl group of benzoic acid was varied (Table 5) in an effort to improve the diastereoselectivity. The best results in terms of diastereoselectivity were obtained with the combination $p$-methoxybenzoic acid/ $N, N^{\prime}$-diphenylthiourea.

Finally, with the most efficient organocatalyst $\mathbf{O C} 4$ at hand we surveyed the scope of this transformation with respect to the aldehyde and the nitroolefin (Table 6). Other aliphatic aldehydes were less reactive and the reaction temperature had to be increased. Linear aliphatic aldehydes reacted with $\beta$-nitrostyrene to provide the Michael adducts in good yields when the reaction was conducted at room temperature. The diastereoselectivity was moderate to good $(\mathrm{dr}=$ 79:21-95:5) in favour of the syn-diastereoisomer and enantioselectivites ranged from $75-84 \%$ ee. The reaction of butyraldehyde with other trans- $\beta$-nitroolefins at room temperature also provided the Michael adducts with moderate to good distereoselectivity $(\mathrm{dr}=74: 26-92: 8)$ in favour of the syn-diastereoisomer and enantioselectivites from $72-84 \%$ ee.

Table 5: Screening of benzoic acids as additives for Michael addition of 3-phenylpropionaldehyde to trans- $\beta$-nitrostyrene using catalysts 0 C4. ${ }^{a}$

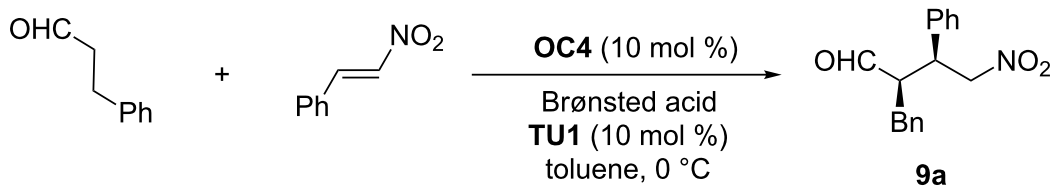

\begin{tabular}{cclc}
\hline Acid & Yield $^{\mathrm{b}}(\%)$ & syn:anti & ee syn ${ }^{\mathrm{c}}(\%)$ \\
\hline $\mathrm{PhCO}_{2} \mathrm{H}$ & 94 & $67: 33$ & 87 \\
$4-\mathrm{MeC}_{6} \mathrm{H}_{4} \mathrm{CO}_{2} \mathrm{H}$ & 89 & $63: 37$ & 86 \\
$4-\mathrm{NO}_{2} \mathrm{C}_{6} \mathrm{H}_{4} \mathrm{CO}_{2} \mathrm{H}$ & 91 & $61: 39$ & 90 \\
$4-\mathrm{FC}_{6} \mathrm{H}_{4} \mathrm{CO}_{2} \mathrm{H}$ & 90 & $63: 37$ & 87 \\
$4-\mathrm{ClC}_{6} \mathrm{H}_{4} \mathrm{CO}_{2} \mathrm{H}$ & 96 & $72: 28$ & 85 \\
$4-\mathrm{MeOC}_{6} \mathrm{H}_{4} \mathrm{CO}_{2} \mathrm{H}$ & 92 & $80: 20$ & 85 \\
\hline
\end{tabular}

aReaction performed using $0.2 \mathrm{mmol}$ of $\beta$-nitrostyrene, $0.4 \mathrm{mmol}$ of 3-phenylpropionaldehyde, $10 \mathrm{~mol} \%$ of OC4, $10 \mathrm{~mol} \%$ of $N, N$-diphenylthiourea,

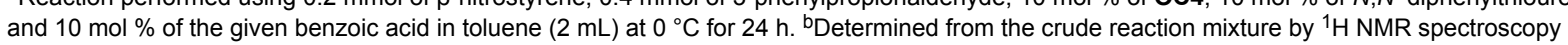
using 1,3,5-trimethoxybenzene as internal standard. ${ }^{\circ}$ Determined by chiral HPLC. 
Table 6: Scope of Michael addition of aldehydes to trans- $\beta$-nitroolefins using catalyst OC4. ${ }^{2}$

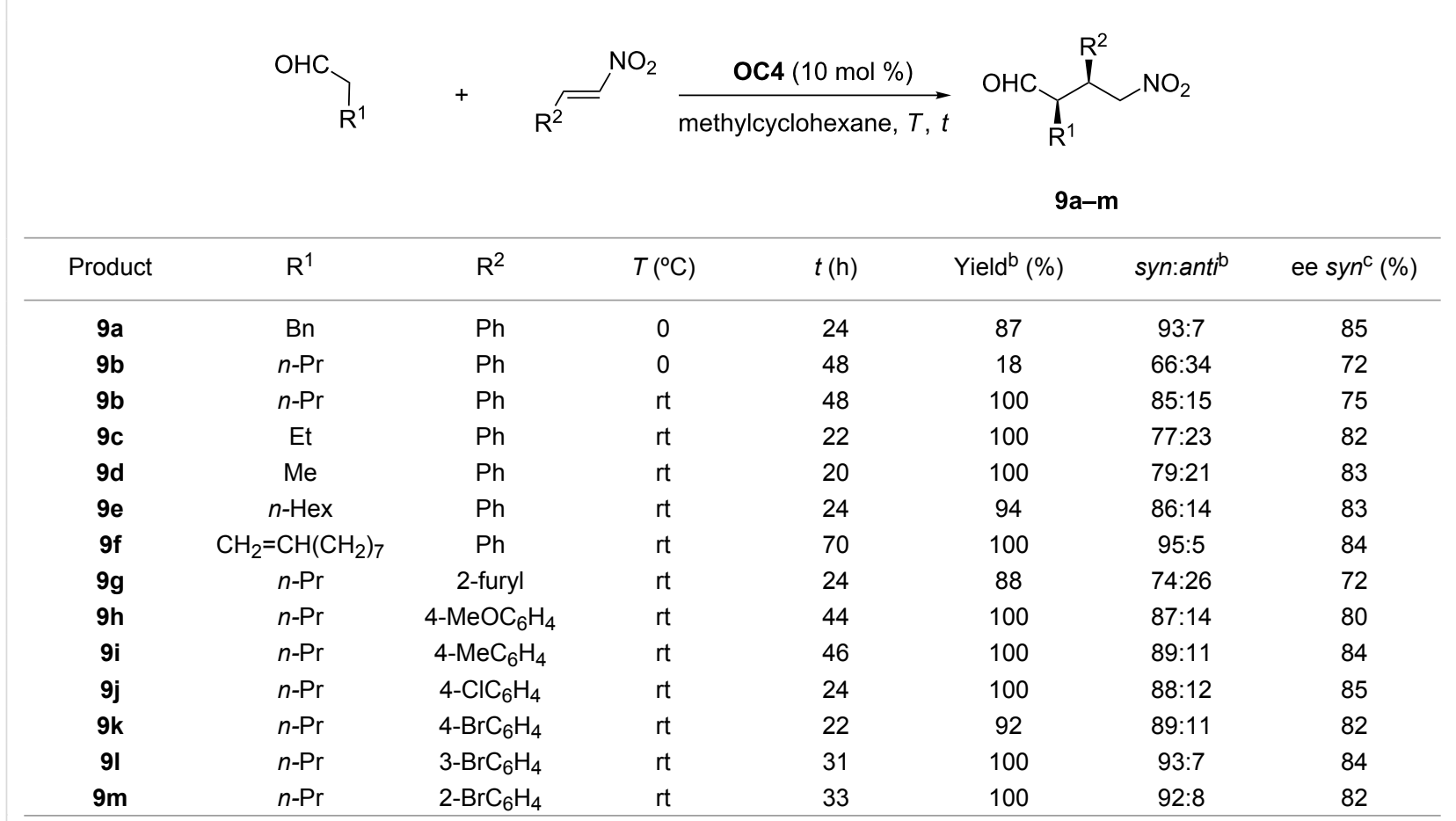

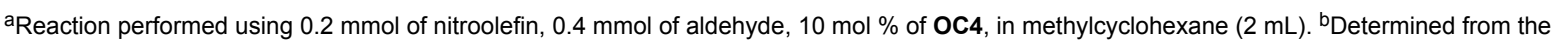
crude reaction mixture by ${ }^{1} \mathrm{H}$ NMR spectroscopy using 1,3,5-trimethoxybenzene as internal standard. ${ }^{\circ}$ Determined by chiral HPLC.

\section{Conclusion}

In conclusion, we have prepared 2-substituted pyrrolidines using a hydrozirconation/iodination reaction of chiral homoallylic amines. The latter were obtained on a multigram scale from imines derived from glyceraldehyde. These easily available compounds are new tuneable organocatalysts with the privileged pyrrolidine motif. When used in the asymmetric Michael addition of aldehydes to nitroolefins, diastereoselectivities of up to $93: 7$ and enantioselectivities of up to $85 \%$ enantiomeric excess for the $s y n$-adduct were obtained in the presence of the most effective organocatalyst $\mathbf{O C 4}$.

\section{Supporting Information}

\section{Supporting Information File 1}

Experimental procedures and characterization data. [http://www.beilstein-journals.org/bjoc/content/ supplementary/1860-5397-13-59-S1.pdf]

\section{Supporting Information File 2}

NMR spectra and HPLC chromatograms.

[http://www.beilstein-journals.org/bjoc/content/ supplementary/1860-5397-13-59-S2.pdf]

\section{Acknowledgements}

Financial support from the Government of Aragón (GA E-102) is acknowledged. A. C. thanks the Government of Aragón for a pre-doctoral fellowship.

\section{References}

1. Dalko, P. I., Ed. Comprehensive Enantioselective Organocatalysis; Wiley-VCH: Weinheim, 2013; Vol. 1-3. doi:10.1002/9783527658862

2. List, B., Ed. Lewis Base and Acid Catalysts; Science of Synthesis: Asymmetric Organocatalysis, Vol. 1; Thieme, 2012. doi:10.1055/b-00000101

3. Maruoka, K., Ed. Brönsted Base and Acid Catalysts, and Additional Topics; Science of Synthesis: Asymmetric Organocatalysis, Vol. 2; Thieme, 2012. doi:10.1055/sos-SD-205-00366

4. Pellisier, H. Recent Developments in Asymmetric Organocatalysis; RSC Catalysis Series 3; Royal Society of Chemistry: Cambridge, 2010. doi:10.1039/9781849731140

5. Zhou, Q.-L., Ed. Privileged Ligands and Catalysts; Wiley-VCH: Weinheim, 2011. doi:10.1002/9783527635207

6. Paz, B. M.; Jiang, H.; Jørgensen, K. A. Chem. - Eur. J. 2015, 21, 1846-1853. doi:10.1002/chem.201405038

7. Holland, M. C.; Gilmour, R. Angew. Chem., Int. Ed. 2015, 54, 3862-3871. doi:10.1002/anie.201409004 Angew. Chem. 2015, 127, 3934-3943. doi:10.1002/ange.201409004 
8. Melchiorre, P.; Marigo, M.; Carlone, A.; Bartoli, G. Angew. Chem., Int. Ed. 2008, 47, 6138-6171. doi:10.1002/anie.200705523 Angew. Chem. 2008, 120, 6232-6265. doi:10.1002/ange.200705523

9. Mukherjee, S.; Yang, J. W.; Hoffmann, S.; List, B. Chem. Rev. 2007, 107, 5471-5569. doi:10.1021/cr0684016

10. List, B. Chem. Commun. 2006, 819-824. doi:10.1039/b514296m

11. Donslund, B. S.; Johansen, T. K.; Poulsen, P. H.; Halskov, K. S.; Jørgensen, K. A. Angew. Chem., Int. Ed. 2015, 54, 13860-13874. doi:10.1002/anie.201503920

Angew. Chem. 2015, 127, 14066-14081. doi:10.1002/ange.201503920

12. Etayo, P.; Badorrey, R.; Díaz-de-Villegas, M. D.; Gálvez, J. A. Adv. Synth. Catal. 2010, 352, 3329-3338. doi:10.1002/adsc.201000594

13. Ahari, M.; Joosten, A.; Vasse, J.-L.; Szymoniak, J. Synthesis 2008, 61-68. doi:10.1055/s-2007-990898

14. Delaye, P.-O.; Ahari, M.; Vasse, J.-L.; Szymoniak, J. Tetrahedron: Asymmetry 2010, 21, 2505-2511. doi:10.1016/j.tetasy.2010.09.015

15. Gálvez, J. A.; Díaz-de-Villegas, M. D.; Badorrey, R.; López-Ram-de-Víu, M. P. Org. Biomol. Chem. 2011, 9, 8155-8162. doi:10.1039/c1ob06216f

16. List, B.; Pojarliev, P.; Martin, H. J. Org. Lett. 2001, 3, 2423-2425. doi:10.1021/ol015799d

17. Betancort, J. M.; Barbas, C. F., III. Org. Lett. 2001, 3, 3737-3740. doi:10.1021/ol0167006

18. Aitken, L. S.; Arezki, N. R.; Dell'Isola, A.; Cobb, A. J. A. Synthesis 2013, 45, 2627-2648. doi:10.1055/s-0033-1338522

19. Díez, D.; Antón, A. B.; García, P.; Garrido, N. M.; Marcos, I. S.; Basabe, P.; Urones, J. G. Tetrahedron: Asymmetry 2008, 19 , 2088-2091. doi:10.1016/j.tetasy.2008.08.025

20. Díez, D.; Antón, A. B.; Peña, J.; García, P.; Garrido, N. M.; Marcos, I. S.; Sans, F.; Basabe, P.; Urones, J. G. Tetrahedron: Asymmetry 2010, 21, 786-793. doi:10.1016/j.tetasy.2008.08.025

21. Hong, L.; Sun, W.; Yang, D.; Li, G.; Wang, R. Chem. Rev. 2016, 116, 4006-4123. doi:10.1021/acs.chemrev.5b00676

22. Patora-Komisarska, K.; Benohoud, M.; Ishikawa, H.; Seebach, D.; Hayashi, Y. Helv. Chim. Acta 2011, 94, 719-745. doi:10.1002/hlca.201100122

23. Rogozińska-Szymczak, M.; Mlynarski, J. Eur. J. Org. Chem. 2015, 6047-6051. doi:10.1002/ejoc.201500913

24. Talavera, G.; Reyes, E.; Vicario, J. L.; Carrillo, L. Angew. Chem., Int. Ed. 2012, 51, 4104-4107. doi:10.1002/anie.201200269 Angew. Chem. 2012, 124, 4180-4183. doi:10.1002/ange.201200269

\section{License and Terms}

This is an Open Access article under the terms of the Creative Commons Attribution License (http://creativecommons.org/licenses/by/4.0), which permits unrestricted use, distribution, and reproduction in any medium, provided the original work is properly cited.

The license is subject to the Beilstein Journal of Organic Chemistry terms and conditions:

(http://www.beilstein-journals.org/bjoc)

The definitive version of this article is the electronic one which can be found at:

doi:10.3762/bjoc. 13.59 